\title{
Performance analysis of ten brands of batteries for hearing aids
}

\author{
Silvio Pires Penteado', Ricardo Ferreira Bento².
}

1) Electronic Engineer, PhD in Medical Science. Department of Otorhinolaryngology, University of São Paulo School of Medicine, São Paulo, Brazil

2) $\mathrm{PhD}$, Professor, Chairman. Department of Otorhinolaryngology, University of São Paulo School of Medicine, São Paulo, Brazil

Institution: Department of Otorhinolaryngology, University of São Paulo School of Medicine

São Paulo / SP - Brazil

Mailing address: Silvio Pires Penteado - Av. Dr. Enéas Carvalho de Aguiar 255, $6^{\text {th }}$ floor - São Paulo / SP - Brazil - ZIP code: $05403-000$ - Telephone: (+55 11) 2661-6539 - E-mail : penteadosp@gmail.com

Financial Support: Fundação Otorrinolaringologia

Article received on February 22 2 th 2013 . Article accepted on April 30 2013.

\section{SUMMARY}

Introduction: Comparison of the performance of hearing instrument batteries from various manufacturers can enable otologists, audiologists, or final consumers to select the best products, maximizing the use of these materials.

Aim: To analyze the performance of ten brands of batteries for hearing aids available in the Brazilian marketplace.

Methods: Hearing aid batteries in four sizes were acquired from ten manufacturers and subjected to the same test conditions in an acoustic laboratory.

Results: The results obtained in the laboratory contrasted with the values reported by manufacturers highlighted significant discrepancies, besides the fact that certain brands in certain sizes perform better on some tests, but does not indicate which brand is the best in all sizes.

Conclusions: It was possible to investigate the performance of ten brands of hearing aid batteries and describe the procedures to be followed for leakage, accidental intake, and disposal.

Keywords: Hearing Aids; Performance Tests; Benchmarking; Batteries; Reference Standards; Laboratory Equipment.

\section{INTRODUCTION}

Dillon (2000) posits that the history of the development of hearing aids can be divided into four eras: the acoustic, carbon valve, transistor, and digital ages. It was only during the first two of these eras that batteries were not needed to power electrical or electronic circuits. Lybarger (1988) states that the first powered hearing aid in the U.S. was produced by Miller Reese Hutchinson in 1902; later, some hearing aids with portable tubes and a drain current of $60 \mathrm{~mA}$ were manufactured. Lybarger describes that the evolution of tubes into transistors brought no significant change in the noise performance of hearing aids; it did, however, drastically reduce battery drain and the size of the batteries required (the drain current was decreased by about 100 times). Modern hearing aids use the topology of transistor analog hearing aids with other electronic circuits that result in devices with better performance and electroacoustic features, but higher power consumption (Cudahy and Levitt, 1994). Kates (2008) states that the digital processor, memory, and analog/digital converter (the internal circuits of the digital signal processor) are responsible for about $70 \%$ of the entire energy consumption of a digital hearing aid.

I Hearing aid batteries based on mercury were gradually replaced by zinc-air batteries, providing positive effects on the environment and advantages for patients (Sparkes and Lacey, 1997). As described by Bloom (2003), "the tiny button cells used in contemporary hearing instruments typically have double the life of the old mercury cells and three times that of silver oxide" and they are "small, lightweight, and leak resistant, offering large capacity, stable voltage, and start-up on demand."

Knutsen (1982) describes a cell as a device for converting chemical energy into electrical energy, with a set amount of voltage and current necessary to power an electrical or electronic circuit. Bocchi, Ferracin, and Biaggio (2000) review the confusion arising from the terms pills and batteries, and state that while the former should be understood as a device consisting of two electrodes and an electrolyte, the second is an association of two or more pills. definitions:

Pinkwart and Tuebke (2011) present the following

1.) Electrode: electrical conductor submerged in electrolyte;

2.) Electrolyte: liquid or gel that contains free ions, which can be decomposed by electrolysis;

3.) Electrolysis: non-spontaneous process in which a direct current is used with the goal of obtaining a chemical reaction;

4.) Anode: the electrode where reduction occurs (to which electrons move towards), known as the positive pole; 
5.) Cathode: the electrode where oxidation occurs (from which electrons move away), also known as the negative pole.

One of the manufacturers of zinc-air batteries (Energizer, 2004) states that electricity is obtained from the following electrolytic reactions:

A.) Anode: $\mathrm{Zn}+2 \mathrm{OH} \rightarrow \mathrm{ZnO}+\mathrm{H} 2 \mathrm{O}+2 \mathrm{e}$

B.) Cathode: $\mathrm{O} 2+2 \mathrm{H} 2 \mathrm{O}+4 \mathrm{e} \rightarrow 4 \mathrm{OH}$

C.) Final: $2 \mathrm{Zn}+\mathrm{O} 2 \rightarrow 2 \mathrm{ZnO}$

Reducing the terms gives the following reaction: $\mathrm{Zn}+\mathrm{O} 2 \rightarrow \mathrm{ZnO}(1)$

Zinc $(\mathrm{Zn})$ particles are mixed with an electrolyte, while water and oxygen in the air react to form hydroxides at the cathode, which migrate to form zincate $\left(\mathrm{Zn}(\mathrm{OH})_{4}{ }^{2-}\right.$ ). Electrons are released and flow to the cathode where reduction produces zincate oxide $(\mathrm{ZnO})$, while water is returned to the system. Water and zinc hydroxide are recycled at the anode for the cathode, so that water serves as a catalyst for the reaction. A typical voltage resulting from this reaction is $1.4 \mathrm{~V}$ (Energizer, 2004). If stored at room temperature without removal of the seal to the air inlet, a zinc-air cell can store $95 \%$ of its capacity for one year, or $90 \%$ of its capacity for up to two years. Valente et al. (2007) state that the positive holes in batteries serve to reset the $\mathrm{O}_{2}$ battery, resulting in electric battery terminals (Formula 1). Zinc-air batteries are practical with good energy density, are stable and safe with a low voltage and current, and must be discarded after use (Wei et al., 2000). Zinc does not harm the environment, is easier to store than other materials (e.g., $\mathrm{O}_{2}$ ), and can be processed in water-based electrochemical systems (Zhang, Bruce, and Zhang, 2011).

IEC60086-1:2006 and IEC60086-2:2006 are applicable to primary batteries and specify their physical dimensions as well as their test conditions and discharge performance requirements. The following terms are taken from the later standard:

I.) Nominal voltage of primary battery: suitable approximate value of voltage used to identify the voltage of a primary battery;

II.) End-point voltage: specified voltage of a battery at which the battery discharge is terminated;

III.) Closed circuit voltage: voltage across the terminals of a battery when it is on discharge;

IV.) Primary cell: one or more primary cells, including case, terminals, and marking;

V.) Storage life: duration under specified conditions at the end of which a battery retains its ability to perform a specified service output;

VI.) Terminals: conductive parts provided for the connection of a battery to external conductors;
VII.) Application test: simulation of the actual use of a battery in a specific application;

VIII.) Off-load voltage: voltage across the terminals of a battery when no current is flowing;

IX.) Service output: service life, or capacity, or energy output of a battery under specified conditions of discharge;

X.) Discharge: operation during which a battery delivers current to an external circuit;

XI.) Leakage: unplanned escape of electrolyte, gas, or other material from a battery.

Halliday and Resnick (1988) report the following definitions:

a.) Voltage-electrical potential: difference between two poles, may be continuous voltage (one pole is always positive and the other always negative) or alternating current (the poles vary in their polarity);

b.) Electrical current: orderly movement of electrons, which can be direct or alternating;

c.) Electrical resistance: electrical component that hinders the passage of electric current, dissipating heat energy to the mean;

d.) Load-end component: circuit that receives electrical current at its terminals;

e.) Recharging the battery: the inverse process to the normal operation of a battery in which tension is applied at its terminals, to recombine the electrolyte to the battery so that it can continue to feed a load.

Digital signal processors force the involuntary shut down of hearing aids when the supply voltage reaches 1.0 $\mathrm{V}$ (SDT, 2007) by ensuring that the voltage is not sufficient to power the electronic circuit, preventing unpredictable behavior and avoiding insufficient amplification or occurrence of spurious signals with high levels of distortion. Kates (2008) states that a battery for a hearing aid should last for at least 50 hours.

As we describe later, even battery manufacturers do not always make the technical data for their batteries available. Only one distributor of hearing aid batteries (Microbattery, 2013) provides an online table comparing the specifications of 10 brands, by presenting the data sheets from various manufacturers. However, this focuses on presenting information for marketing purposes in order to promote sales through their website.

With this information in mind, it can be seen that it is difficult for otologists and audiologists to recommend the brand of hearing aid battery with the best performance to patients. Factors such as patient comparisons of battery brand durability, the risk of battery leaks and how to deal with them, procedures to use in the case of ingestion, how to dispose of hearing aid batteries, whether zinc-air 
batteries can be recharged, and if rechargeable batteries fully replace zinc-air batteries have not been fully investigated. There are no publications in the literature addressing these basic concerns, although some information can be found in scientific publications and lay media.

Thus, we attempted to address the above concerns and develop laboratory tests for the practical purpose of comparing the performance of 4 different sizes of 10 brands of batteries for hearing aids that can be found in the Brazilian marketplace. We did not conduct a financial analysis between zinc-air batteries and rechargeable batteries. The primary objective of this research was to investigate the performance of 10 brands of hearing aid batteries under the same test conditions. The secondary objectives were to describe courses of action to be taken for battery leaks, accidental intake, and disposal.

\section{METHOD}

This study was performed in the Laboratory of Acoustics at the Department of Otorhinolaryngology between June 17, 2011 and February 5, 2012.

\section{Battery acquisition}

Hearing aid batteries can be found in sizes \#675, $\# 13$, \#312, \#10, and \#5 (in descending size). In the Brazilian marketplace, it is hard to find hearing aids with batteries of size $\# 5$, so this size was not tested in the current study. Before battery acquisition, we performed a quick survey of experienced audiologists to determine which brands of hearing aid batteries were most used by them, and which brands patients recommended. With this information, manufacturers, dealers, and distributors were contacted by mail with a standard message, and, depending on the manufacturer, they sent us samples, data sheets, material safety data sheets, and marketing material. For example, Mazalab (ExtraPower) sent a free pack of batteries but no technical documents, while Ammon \& Rizos (Renata) sent a battery pack and the respective data sheets. Although a survey of all the manufacturers was conducted, some did not provide data sheets for their products, namely ExtraPower, ClearCell, PowerOne (specifications only), and Sony. Possession of data sheets allowed observation of common technical standards and a direct comparison of the performance of batteries from several manufacturers. All the battery suppliers were located in the city of São Paulo. The six suppliers contacted are listed in Chart 1 . The last three vendors listed in the chart donated their batteries, while the others sold them at retail value.

\section{Battery identification}

Hearing aid pills are commonly marketed as batteries; therefore, we refer to pills, cells, and batteries as batteries in this work. Once the batteries were checked they were identified as ExtraPower (A), ClearCell (B), PowerOne (C), Renata (D), Energizer (E), Duracell (F), Rayovac (G), icellTech (H), Sony (I), or Panasonic (J). Theseidentifications made it possible to avoid any confusion concerning the manufacturer and model, and were marked on the batteries with a knife. This marking system did not cause the exchange of heat with the batteries and thus did not change the electrolytes inside the batteries. Figure 1 shows a \#675 battery by ExtraPower. Figure 2 shows a \#675 battery by ClearCell viewed under a microscope. Two packs were acquired from each of the manufacturers listed in Chart 1 so that we could retest any of the batteries as required (Figure 1 and 2).

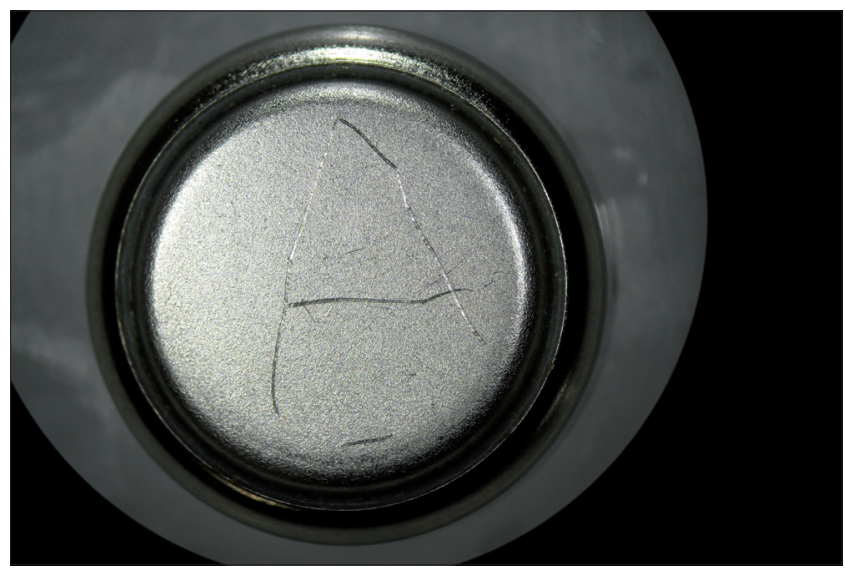

Figure 1. ExtraPower \#675 identification.

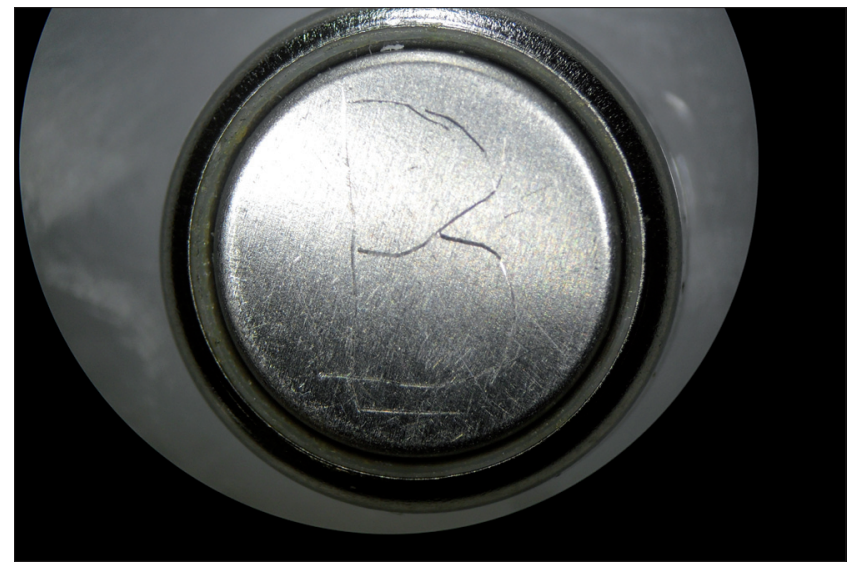

Figure 2. ClearCell \#675 identification. 
Chart I. General battery information.

\begin{tabular}{|c|c|c|c|c|c|c|c|c|}
\hline Supplier & $\begin{array}{c}\text { Manufacturer/ } \\
\text { brand }\end{array}$ & Model & Size & $\begin{array}{l}\text { Identification/ } \\
\text { designation }\end{array}$ & $\begin{array}{c}\text { Nominal } \\
\text { voltage } \\
\text { (V) }\end{array}$ & $\begin{array}{l}\text { Service } \\
\text { output } \\
\text { (mAh) }\end{array}$ & $\begin{array}{l}\text { Quantity/ } \\
\text { pack }\end{array}$ & $\begin{array}{l}\text { Best } \\
\text { before }\end{array}$ \\
\hline \multirow[t]{8}{*}{ Digitall } & \multirow[t]{4}{*}{ Panasonic } & PR675H & 675 & PR-675HEP/6C & 1.4 & 605 & 6 & $10 / 2013$ \\
\hline & & PRI3H & 13 & $\mathrm{PHI}$ HHEP/6C & 1.4 & 300 & 6 & $09 / 2013$ \\
\hline & & PR3 12 & 312 & PR-3 I $2 \mathrm{HEP} / 6 \mathrm{C}$ & 1.4 & 170 & 6 & $10 / 2013$ \\
\hline & & PR230H & 10 & PR-230HEP/6C & 1.4 & 65 & 6 & $05 / 2013$ \\
\hline & \multirow[t]{4}{*}{ icellTech } & Platinum & 675 & PR44 & 1.4 & 630 & 6 & $10 / 2013$ \\
\hline & & Platinum & 13 & PR48 & 1.4 & 310 & 6 & $12 / 2013$ \\
\hline & & Platinum & 312 & PR4I & 1.4 & 180 & 6 & $05 / 2013$ \\
\hline & & Digital Sound & 10 & PR70 & 1.4 & 105 & 6 & $05 / 2012$ \\
\hline \multirow[t]{16}{*}{ Joave } & \multirow[t]{4}{*}{ Sony } & 675 & 675 & 675(PR44) & 1.4 & $\mathrm{Nl}$ & 6 & $02 / 2014$ \\
\hline & & 13 & 13 & I3(PR48) & 1.4 & $\mathrm{NI}$ & 6 & $10 / 2014$ \\
\hline & & 312 & 312 & 312 (PR4I) & 1.4 & $\mathrm{Nl}$ & 6 & $10 / 2013$ \\
\hline & & 10 & 10 & IO(PR70) & 1.4 & $\mathrm{NI}$ & 6 & $10 / 2014$ \\
\hline & \multirow[t]{4}{*}{ Duracell } & Activair & 675 & PR44 & 1.4 & 600 & 4 & $08 / 2014$ \\
\hline & & Activair & 13 & PR48 & 1.4 & 290 & 4 & $1 / / 2014$ \\
\hline & & Activair & 312 & PR4I & 1.4 & 150 & 4 & $|2 / 20| 4$ \\
\hline & & Activair & 10 & PR70 & 1.4 & 90 & 4 & $02 / 2015$ \\
\hline & \multirow[t]{4}{*}{ Energizer } & AudioPRO & 675 & AC675-4AP & 1.4 & 635 & 4 & $10 / 2012$ \\
\hline & & AudioPRO & 13 & ACI3-4AP & 1.4 & 280 & 4 & $10 / 2013$ \\
\hline & & AudioPRO & 312 & $A C 312-4 A P$ & 1.4 & 160 & 4 & $07 / 2012$ \\
\hline & & AudioPRO & 10 & ACI0-4AP & 1.4 & 91 & 4 & $01 / 2012$ \\
\hline & \multirow[t]{4}{*}{ PowerOne } & PowerOne & 675 & p675 & 1.4 & 650 & 6 & $07 / 2013$ \\
\hline & & PowerOne & 13 & pl3 & 1.4 & 310 & 6 & $01 / 2014$ \\
\hline & & PowerOne & 312 & p312 & 1.4 & 180 & 6 & $01 / 2014$ \\
\hline & & PowerOne & 10 & pl0 & 1.4 & 100 & 6 & $01 / 2014$ \\
\hline \multirow[t]{4}{*}{ CTEA } & \multirow[t]{4}{*}{ Rayovac } & ExtraAdvanced & 675 & 675AE-6LD & 1.45 & $\mathrm{NI}$ & 6 & $06 / 2014$ \\
\hline & & ExtraAdvanced & 13 & $13 A E$ & 1.45 & $\mathrm{NI}$ & 6 & $08 / 2014$ \\
\hline & & ExtraAdvanced & 312 & $312 A E-6 L D$ & 1.45 & $\mathrm{NI}$ & 6 & $01 / 2014$ \\
\hline & & ExtraAdvanced & 10 & I0AE-6LD & 1.45 & $\mathrm{Nl}$ & 6 & $10 / 2014$ \\
\hline \multirow[t]{4}{*}{ SANCIEX } & \multirow[t]{4}{*}{ ClearCell } & Premium & 675 & 675 & 1.4 & 630 & 4 & $10 / 2013$ \\
\hline & & Premium & 13 & 13 & 1.4 & 300 & 4 & $10 / 2013$ \\
\hline & & Premium & 312 & 312 & 1.4 & 180 & 4 & $10 / 2013$ \\
\hline & & Premium & 10 & 10 & 1.4 & 100 & 4 & $10 / 2013$ \\
\hline \multirow[t]{4}{*}{ MazaLab } & \multirow[t]{4}{*}{ ExtraPower } & ExtraPower & 675 & A675 & 1.4 & 630 & 6 & $12 / 2013$ \\
\hline & & ExtraPower & 13 & Al3 & 1.4 & 300 & 6 & $07 / 2013$ \\
\hline & & ExtraPower & 312 & $\mathrm{~A} 312$ & 1.4 & 180 & 6 & $07 / 2013$ \\
\hline & & ExtraPower & 10 & AlO & 1.4 & 100 & 6 & $07 / 2013$ \\
\hline \multirow[t]{4}{*}{ Ammon \& Rizos } & \multirow[t]{4}{*}{ Renata } & Maratone+ & 675 & ZA675 & 1.4 & 650 & 6 & $05 / 2013$ \\
\hline & & Maratone+ & 13 & ZAI3 & 1.4 & 310 & 6 & $1 / / 2013$ \\
\hline & & Maratone+ & 312 & ZA312 & 1.4 & 180 & 6 & $03 / 2014$ \\
\hline & & Maratone+ & 10 & ZAIO & 1.4 & 100 & 6 & $05 / 2014$ \\
\hline
\end{tabular}

NI - not informed.

\section{Tests details}

Tests were initialized 10 days after the receipt of all the batteries so that the effects of storage in the laboratory did not alter the performance of the batteries. With the possession of data sheets, it was observed that there is no standardization for performance evaluation. For example, Renata \#675 follows standard IEC60086-2, which prescribes a discharge cycle of 12 hours in a load resistor of $619 \Omega$ followed by a subsequent 12 hours of rest (for chemical recombination with subsequent partial recovery), with a temperature and humidity of $21^{\circ} \mathrm{C}$ and $50 \%$, respectively. icellTech $\# 675$ prescribes a discharge cycle of 16 hours in a load resistor of $620 \Omega$ followed by 8 hours of rest, with an ambient temperature of $25^{\circ} \mathrm{C}$ and a relative humidity of $50 \%$, without mentioning any standard. Therefore, we chose to use fixed and high precision resistors (Chart 2) to simulate a fixed load in a 
closed circuit voltage along with a prescribed discharge cycle of 12 hours followed by a subsequent 12 hour rest period. Both the values of the resistors, the charge and the discharge cycle, meet the requirements of IEC600862 (Table 7.4.2. in this standard) pertaining to each of the battery sizes.

Neither the temperature nor the humidity was controlled by an air conditioning system, on account of the fact that the laboratory where the tests were conducted does not have a precision system, only a split air conditioning system. However, both the temperature and the relative humidity were monitored by a Minipa hygrometer (MT241), and measurements were recorded randomly during testing (lowest 45\%, highest 74\%). We used a calibrated Minipa multimeter (ET-2042C) to measure voltages.

All battery seals were removed from zinc-air batteries and the batteries were then left for 10 minutes for activation (Renata ref. ZA675 Maratone+ Rev. 3/January 2009), although Energizer (2004) recommends 30 seconds for the same procedure.

It was necessary to assemble a test jig (Figure 3), i.e., a dedicated device for assisting in the evaluation of battery performance. For the construction of the test jig, only discrete components such as resistors, relays, switches, fuses, and connectors were used, and the logical drive was handled by an EcoGold programmable timer (EG-TMR009; Figure 4).

The general scheme of operation of the jig can be seen in Figure 5.

A closed circuit composed of a resistor and a relay (in which electrical contacts opened or closed its corresponding circuit) was used to test each battery individually. This design met the specifications of IEC60086-2 fixed-charge. Thus, the battery (P1) fed the load resistor (R1; as shown in Chart 1) by contact S1 (K1 relay). This configuration was repeated 24 times. A general key (S) enabled or did not enable the circuit, while a fuse (F) protected against test jig overcurrent. A direct current supplier (P; AC to DC converter) fed the relay coils, according to the schedule set in the programmable timer $(\mathrm{T})$. The timer was powered by mains $110 \mathrm{~V}$ conventional $\mathrm{R}$.

Through the test jig, it was possible to test two batteries of each brand simultaneously. Two batteries of each brand were used in simultaneous testing so that the worst of the two values could be excluded; thus, only the best performance for each of the sizes and brands of each battery was considered. In this way, up to 44 batteries were tested simultaneously in the test jig.
Chart 2. Resistor values for closed circuit voltage simulation.

\begin{tabular}{lcc}
\hline Batterysize & Load resistor $(\Omega)$ & Precision $(\%)$ \\
\hline$\# 675$ & 620 & 1 \\
$\# 13$ & 1500 & 2 \\
$\# 312$ & 1500 & 2 \\
$\# 10$ & 3000 & 1 \\
\hline
\end{tabular}

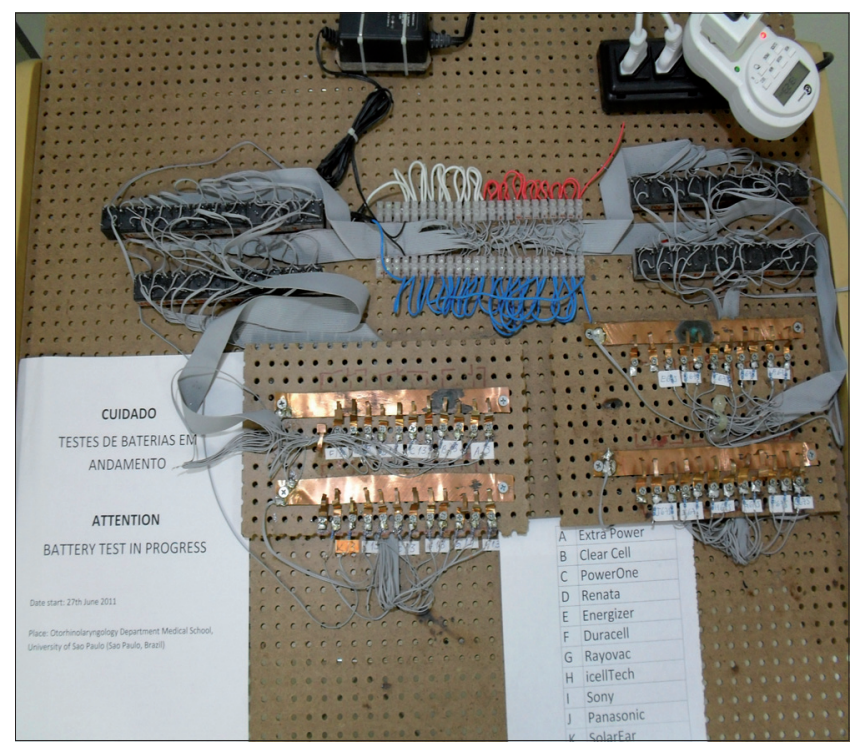

Figure 3. Test jig, top view.

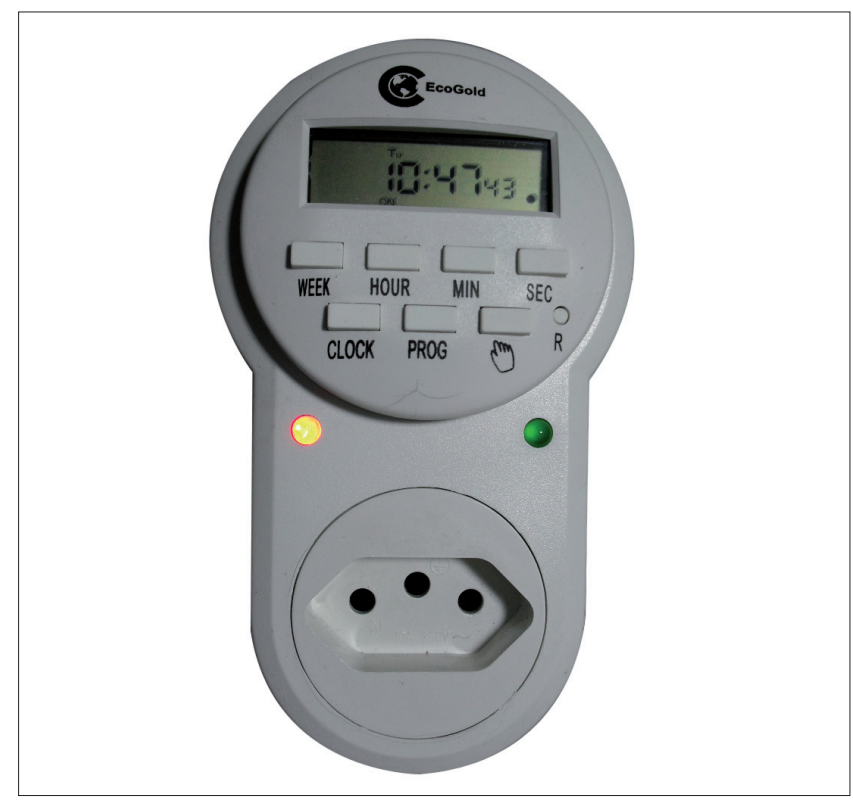

Figure 4. Programmable timer, top view. 


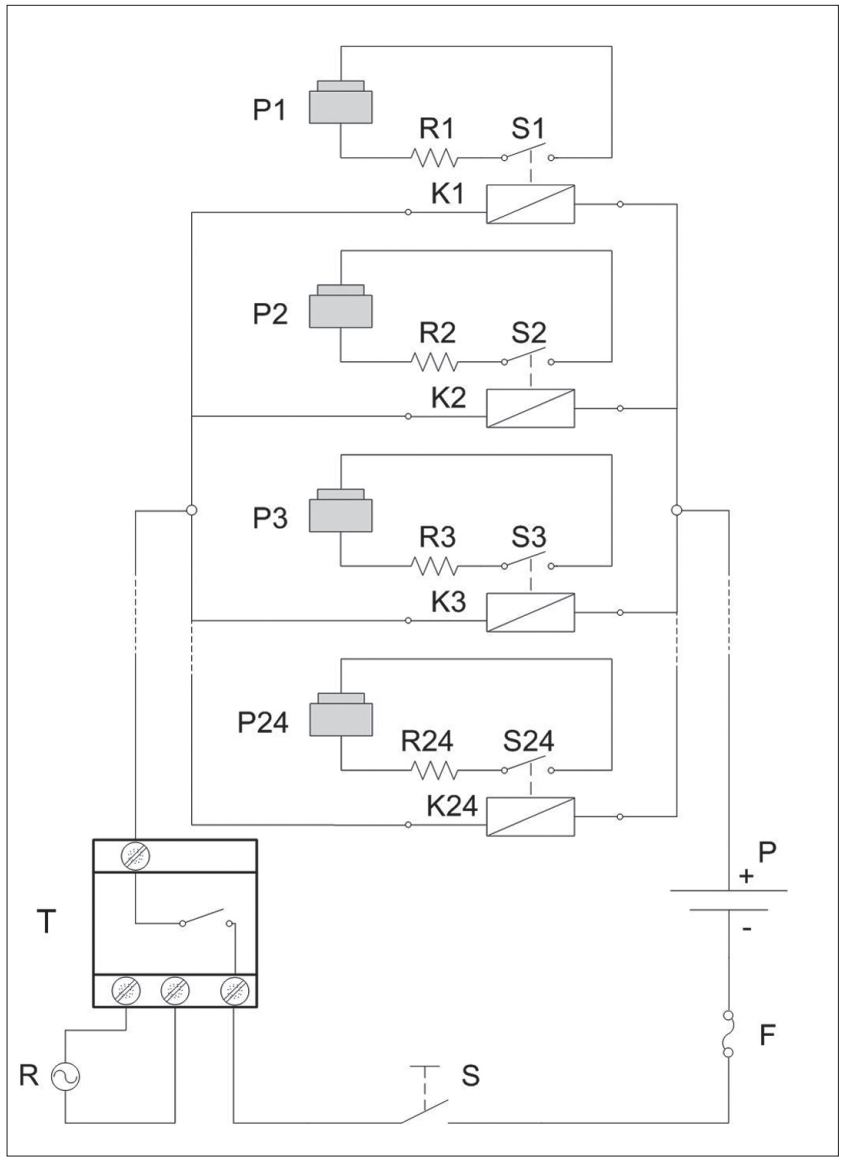

Figure 5. Simplified schematics implemented in the test jig.

Toensure that each circuit was functioning individually, the multimeter was used to verify if there was voltage across each of the resistors, which indicated that the circuit was functioning correctly. Twice daily voltage measurements were performed in a random order at each of the resistors.

After measuring the initial voltages of the batteries without load (open circuit voltage), they were then subjected to load (closed circuit). These cycles were alternated in accordance with a prescribed logic, to assess how many hours a battery would last until its final voltage of $1.1 \mathrm{~V}$. This was followed by four more measurements, in order to ensure that once a battery had reached this value, it was unable to supply voltage (end-point voltage). The value of $1.1 \mathrm{~V}$ was used as the cutoff voltage because it was higher than the amount proposed by SDT (2007) with some safety margin and, in general, it is observed that values below $1.1 \mathrm{~V}$ can cause unpredictable behavior of hearing aids. In addition, the manufacturers' data sheets showed that at around this value, zinc-air batteries have virtually no more capacity for power supply.

Accordingly, the programmable timer was set to energize the test jig at 10:05 am following a discharge cycle of 12 hours, which peaked at 8:05 am on the next morning.
Measurements were conducted immediately, following the sequence A, B, C, (..) until the last battery. The next day, measurements started with the last battery and followed the sequencebackwards to battery A. On holidays, Saturdays, and Sundays the building facilities were closed, thus a different procedure was required. The night before a holiday, Saturday, or Sunday, 15 minutes was added to the programmable timer, so as to allow any additional battery discharge before measurements. Therefore, we sought to offset the effects of partial recombination charge, which could have masked the last readings of voltage, especially at the beginning of testing, when the batteries had a higher capacity for recombination of partial charge.

All batteries were tested under this scheme. A flowchart detailing the logic employed in the test is shown in the Annex.

To record images, we used a Leica binocular microscope (EZ4) and a Samsung digital camera (SL30).

\section{RESULTS}

The results are graphs 1 to 4 and Table 1 .

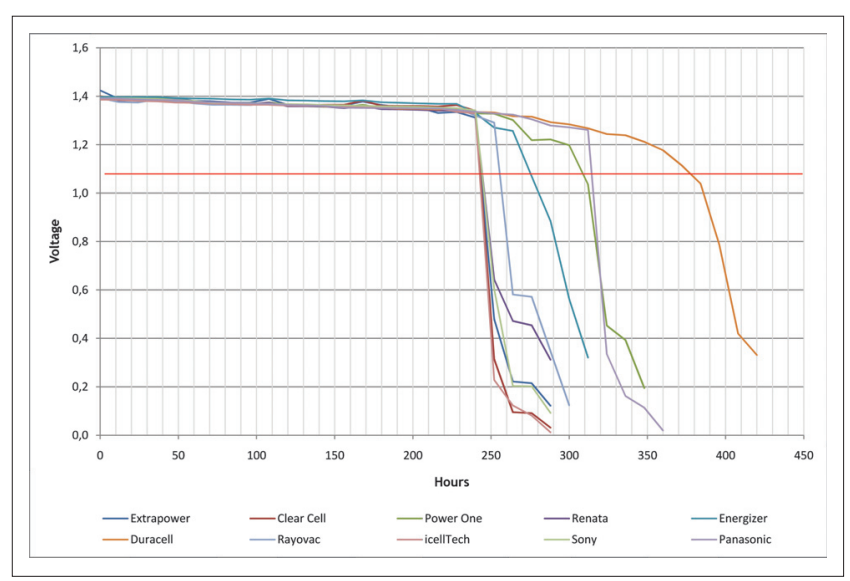

Graphic 1. Discharge curve of zinc-air size $\# 675$.

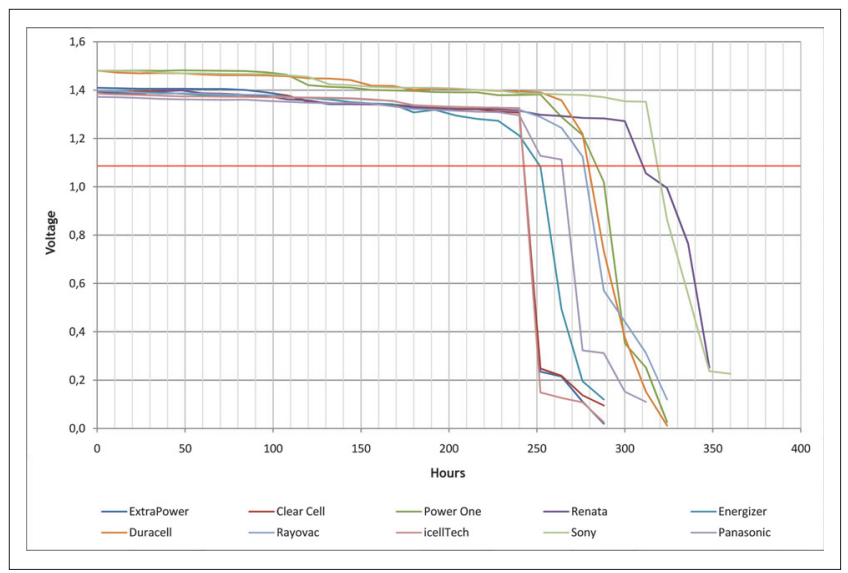

Graphic 2. Discharge curve of zinc-air size \#13. 


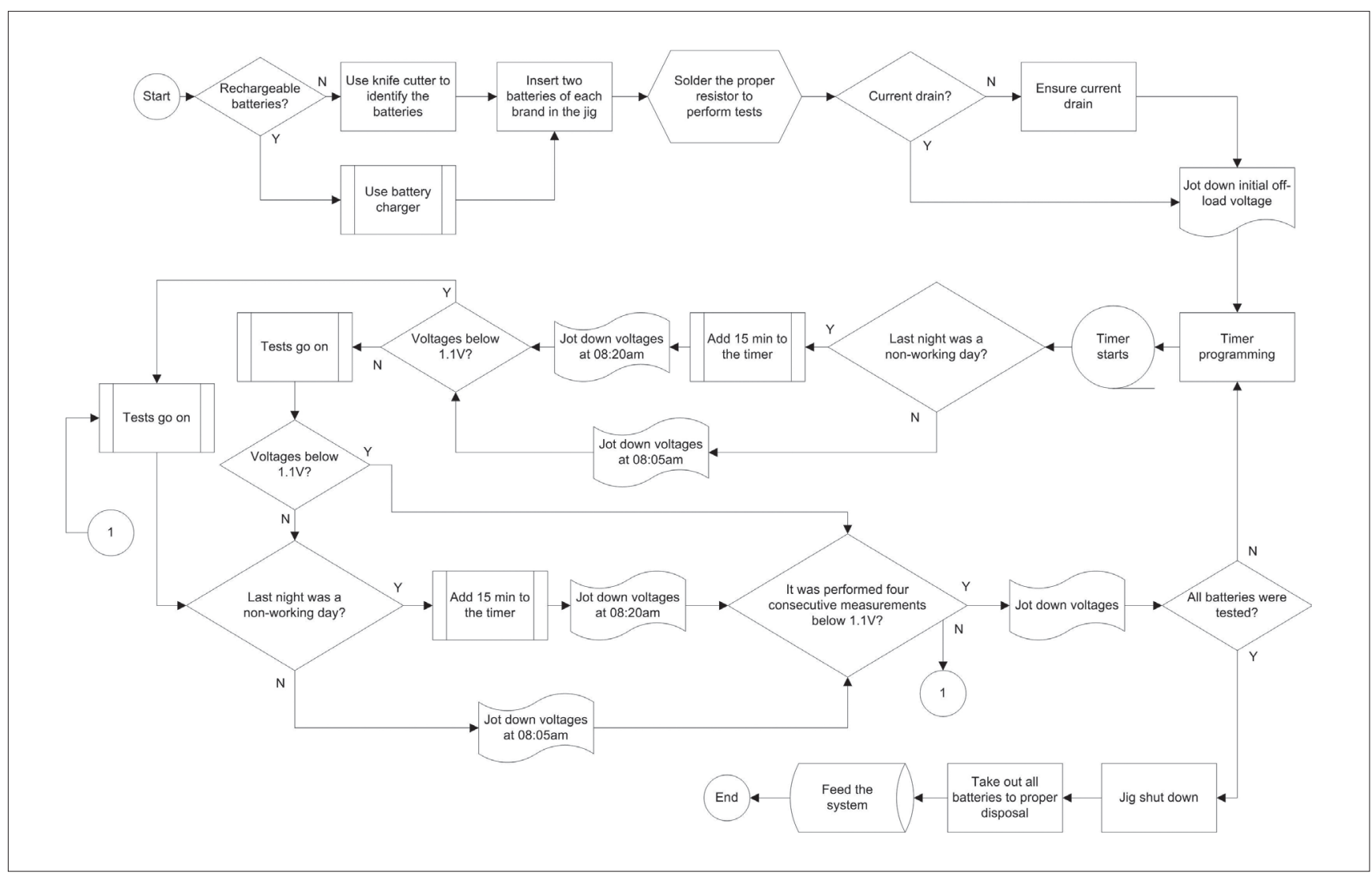

Annex. Logic implemented on tests

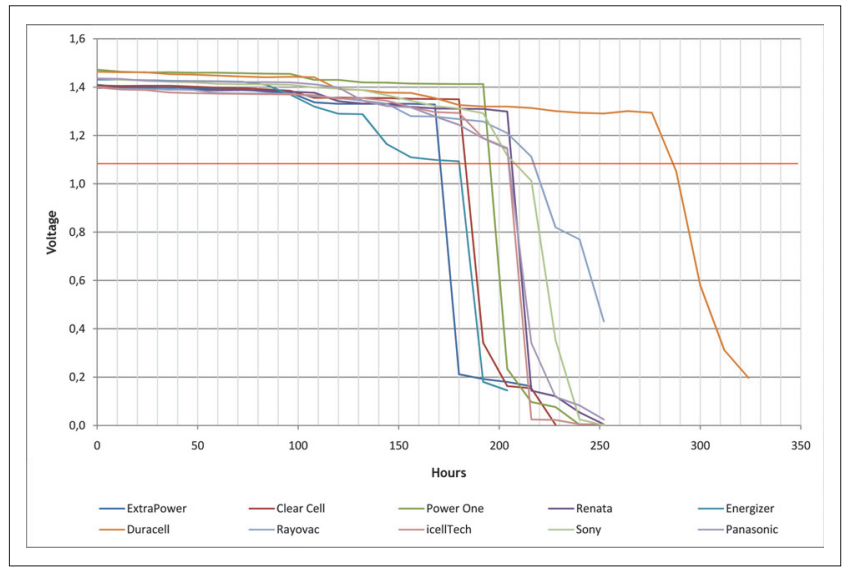

Graphic 3. Discharge curve of zinc-air size \#312.

Table I. Zinc-air battery values (average and standard deviation).

\begin{tabular}{lcc}
\hline Size & Averageservice(hours) & Nominalvoltage(volts) \\
\hline$\# 675$ & $(270 \pm 45)$ & $(1.357 \pm 0.039)$ \\
$\# 13$ & $(266 \pm 26)$ & $(1.376 \pm 0.057)$ \\
$\# 312$ & $(199 \pm 32)$ & $(1.370 \pm 0.068)$ \\
$\# 10$ & $(245 \pm 15)$ & $(1.339 \pm 0.067)$ \\
\hline
\end{tabular}

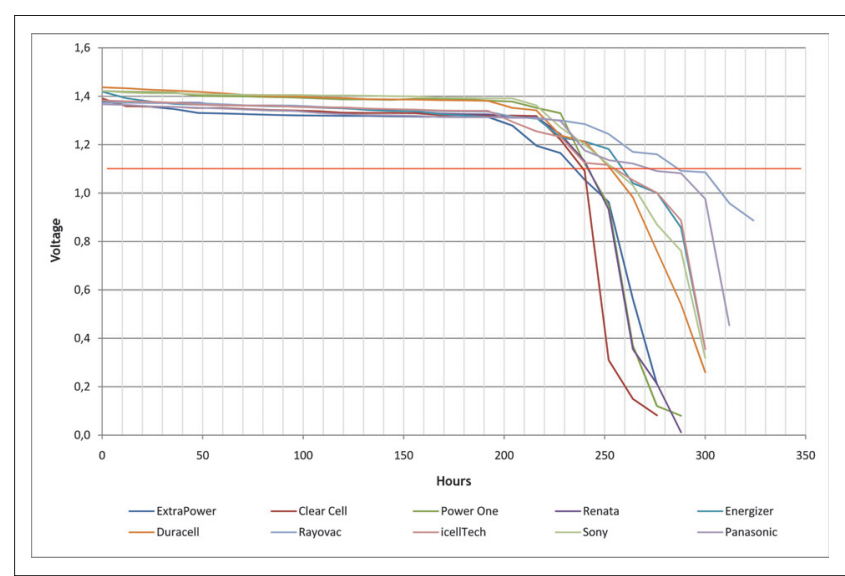

Graphic 4. Discharge curve of zinc-air size \#10.

\section{DISCUSSION}

The necessity to use a standard for evaluating the performance of hearing aid batteries may be questioned, since such evaluation can be performed by experienced patients or driven by engineers. For example, each patient has a need for selective amplification, and amplification is 
related to battery consumption in the following ratio: the higher the amplification, the greater the battery drain. In general, the batteries tested in the current study had the capacity to supply power for up to 270 hours (Table 1 ). This means that patients would need to continue to test batteries under the same conditions for about 22 days ( 270 hours divided by 12 hours/day). It would be a hindrance to the patient to maintain rigorous battery use at the same volume for 22 consecutive days. Furthermore, this procedure would have to be repeated for all brands in the four sizes of batteries available. Battery drain varies greatly with acoustic feedback. When a hearing aid mold is not well coupled to the ear (BTE design hearing aid cases), this is enough to produce feedback. Tests conducted in our laboratory indicate that when feedback occurs, hearing aids have a current drain ( $4.34 \mathrm{~mA}$, Figure 7$)$ several times higher than a hearing aid without feedback $(0.94 \mathrm{~mA}$, Figure 6). Thus, while tests with patients may directly transcribe their views, assessment of hearing aid batteries demands specialized and sequentially standardized testing, which is only possible using application tests in a laboratory.

The objectives of the present study included testing batteries within the conditions prescribed by IEC60086-1, IEC60086-2, and IEC60086-3; however, this was not always possible since the laboratory where this study was performed is not one of a certifying body, but one of a battery consumer. For example, the above referenced IEC standards require testing of nine batteries of the same brand and model (this study tested two batteries of each brand and model), and combine the measurement of physical battery size with electrical testing with fixed load (performed in this study) and load with standard and high pulse drain (not performed in this study). Additionally, both the temperature and the relative humidity should vary only under restricted margins, which can be seen in Tables 4 and 7 of IEC600861. In this regard, the storage temperature of batteries must be between $+10^{\circ} \mathrm{C}$ and $+25^{\circ} \mathrm{C}\left(50^{\circ} \mathrm{F}\right.$ and $77^{\circ} \mathrm{F}$, respectively), and should never exceed $+30^{\circ} \mathrm{C}\left(86^{\circ} \mathrm{F}\right)$, which makes storage at low temperatures $\left(-10^{\circ} \mathrm{C}\right.$ up to $+10^{\circ} \mathrm{C}$ or $14^{\circ} \mathrm{F}$ up to $50^{\circ} \mathrm{F}$ ) ideal, either for testing purposes or for marketing purposes.

However, Annex G of IEC60086-1 defines that any battery consumer can establish a standard methodology for measuring the performance of batteries (SMMP) that meets the following criteria:

a) The test methods should be defined in such a way that the test results correspond as closely as possible to the performance results as experienced by consumers when using the product in practice;

b) It is essential that the test methods are objective and give meaningful and reproducible results;

c) Details of the test methods should be defined with a view to optimum usefulness to the consumer, taking

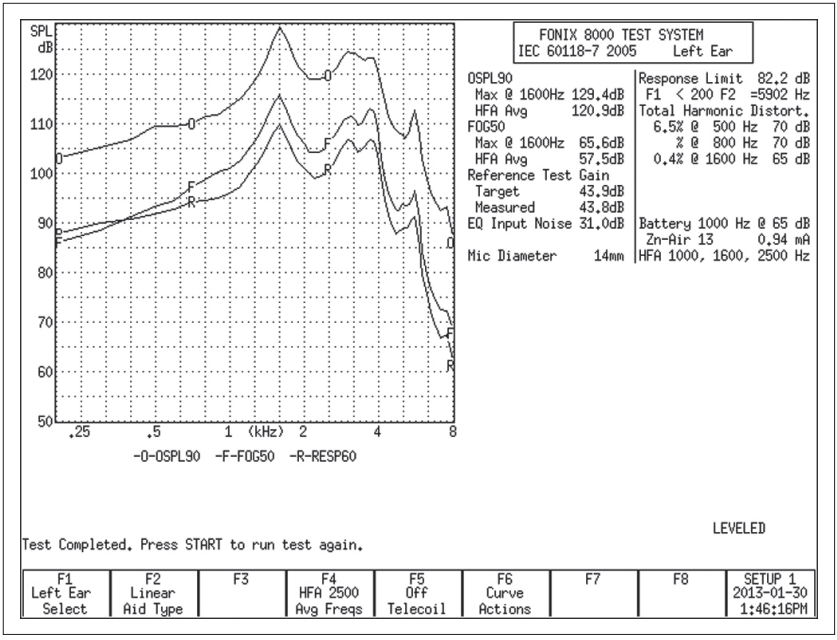

Figure 6. Hearing aid curves without feedback.

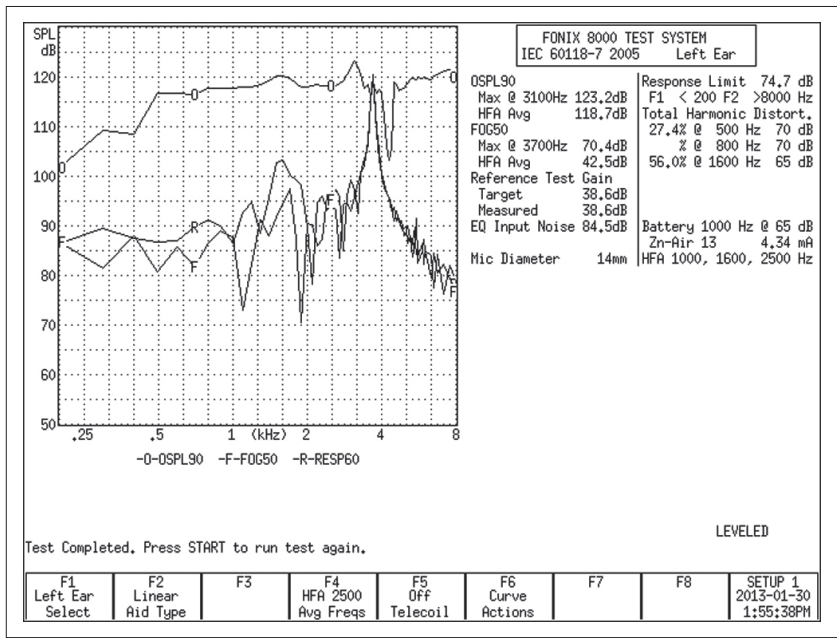

Figure 7. Hearing aid curves with feedback.

into account the ratio between the value of the product and the expenses involved in performing the tests;

d) Where use has to be made of accelerated test procedures, or of methods that have only an indirect relationship to the practical use of the product, the technical committee should provide the necessary guidance for correct interpretation of test results in relation to normal use of the product.

The present study meets the above criteria, so its results allow a performance analysis comparison between batteries of various brands.

It was observed that battery manufacturers do not always provide data sheets for their products, making it difficult to compare the performance of various battery brands. The data sheets that were provided did not follow a specific standard, which again made it difficult to compa- 
re the results obtained in this experiment with the manufacturers' data. Among the restrictions for comparison of performance, it was found that the documentation provided by PowerOne transcribed only a few numerical specifications (voltage, typical energy, and capacity), and thus abstained from describing the dynamic behavior of the battery. This can be described by graphs, in a similar way to the data sheets provided by Renata, Energizer, Duracell, Rayovac, and icellTech. The Panasonic data sheet only showed dynamic curves of high drain, resulting in a disturbing and misguided image of low battery performance for this manufacturer.

Comparing the manufacturers' data sheets with the curves obtained in the current study highlighted many discrepancies. To this end, we inserted a line parallel to the abscissa axis until it crossed the voltage of $1.1 \mathrm{~V}$ both in the graphs provided in data sheets and the graphs obtained using the procedure described in this study. Thus, the discharge time was defined as the time (in hours) that the batteries provided voltage above $1.1 \mathrm{~V}$. The following table shows the data for each battery from each of the manufacturers.

From Table 2 it can be seen that for batteries of size $\# 675$, there was large variation between the values listed in the data sheets (lowest value $=110$ hours, highest value $=560$ hours) compared to the values measured in this study (lowest value $=240$ hours, highest value $=372$ hours). While the average service measured in this study (Table 1) was (270 \pm 45$)$ hours, the average service from the data sheets (Table 2) was ( $290 \pm 161)$ hours.

Table 2 also shows that batteries of size $\# 13$ showed wide variation in their data sheets (lowest value $=140$ hours, highest value $=440$ hours) when compared with the values obtained in this study (lowest value $=240$ hours, highest value $=300$ hours). Table 1 indicates that the average service measured was ( $266 \pm 26$ ) hours, while the data sheets (Table 2) showed a final measurement of (306 $\pm 107)$ hours.

Regarding batteries of size \#312, there was great variability among the values of the data sheets (lowest value $=140$ hours, highest value $=360$ hours) compared to the values obtained in this study (lowest value $=156$ hours, highest value $=276$ hours). The average service measured was $(199 \pm 32)$ hours, whereas the same parameter from the data sheets (Table 2) was (204 \pm 88 ) hours.

Finally, the data sheets for batteries of size $\# 10$ showed considerable variation (lowest value $=130$ hours, highest value $=360$ hours) compared to the values obtained by measurements made in this study (lowest
Table 2. Average service time taken from the manufacturers' data versus the results of the current study.

\begin{tabular}{lcccc}
\hline Manufacturer & Size & $\begin{array}{c}\text { Average } \\
\text { service } \\
\text { (hours) }\end{array}$ & $\begin{array}{c}\text { Average } \\
\text { service }^{2} \\
\text { (hours) }\end{array}$ & $\begin{array}{c}\text { Difference } \\
(\%)\end{array}$ \\
\hline Renata & $\# 675$ & 560 & 240 & 57 \\
Energizer & $\# 13$ & 440 & 300 & 32 \\
& $\# 312$ & 360 & 204 & 43 \\
& $\# 10$ & 360 & 240 & 33 \\
Duracell & $\# 13$ & 290 & 264 & 9 \\
& $\# 312$ & 180 & 240 & 23 \\
& $\# 10$ & 190 & 252 & 13 \\
& $\# 675$ & 280 & 372 & -33 \\
Rayovac & $\# 13$ & 310 & 286 & 8 \\
& $\# 312$ & 170 & 276 & -62 \\
& $\# 10$ & 180 & 252 & -40 \\
& $\# 15$ & 110 & 252 & -129 \\
icellTech & $\# 13$ & 140 & 276 & -97 \\
& $\# 10$ & 140 & 204 & -46 \\
& $\# 675$ & 290 & 240 & -112 \\
& $\# 13$ & 330 & 240 & 27 \\
& $\# 312$ & 170 & 204 & -20 \\
& $\# 10$ & 208 & 252 & -21 \\
\hline
\end{tabular}

Notes:

I.) Datafrom manufacturers' data sheets;

2.) Data from the currentstudy.

value $=240$ hours, highest value $=276$ hours . The data in Table 1 show that the average service obtained in this study was ( $245 \pm 15$ ) hours, whereas the data sheets (Table $2)$ indicated a value of $(214 \pm 87)$ hours for the same parameter.

Taken together, the information provided above highlights the fact that there was a large variability in the values presented in the manufacturers' data sheets, while laboratory test results reflected a lower variability, which confirms the reliability of tests performed in the laboratory. Asymmetric information was provided in data sheets, e.g., the data sheet of one manufacturer (icellTech \#675) had an average service of 290 hours and that for a battery of the same size but from another manufacturer (Renata) had an average service of 560 hours ( $93 \%$ variation). It is not clear what the technological aspects were that enabled this intriguing variation in performance from one manufacturer to the other, since it is assumed that existing technology was not manipulated in a significantly different way. For example, when these batteries were subjected to the same dynamic tests, both had a discharge time of 240 hours. In addition, with regards to batteries of size $\# 675$, it is difficult to explain how Rayovac battery data sheets showed an average service of only 110 hours, as compared to 290 
hours and 560 hours in the data sheets of Renata and icellTech, respectively. In dynamic testing, Rayovac batteries had an average service of 252 hours, which was close to the values registered for Renata and icellTech batteries (240 hours). Similar results were obtained with other batteries.

In a similar way, the data sheet for size \#13 Rayovac batteries reported an average service of 140 hours, while Renata's data sheet stated a service of 440 hours, which is a variation of more than 200\%. When this was measured dynamically, the values changed by 25\% (240 hours and 300 hours, respectively). Similar results were observed with respect to batteries of size \#312, since the Renata data sheets reported an average service of 380 hours, Rayovac's stated a service of 140 hours, and icellTech's stated a service of about 170 hours, whereas the dynamic values obtained in this study indicated a service time of 204 hours. A similar result was also found with respect to size \#10 batteries: the data sheet from Renata stated an average service of 370 hours, whereas those from Energizer and Duracell stated 190 hours and 200 hours, respectively. Laboratory tests indicated the values of 240, 252, and 252 hours, respectively.

The American brands Energizer, Duracell, and Rayovac have data sheets referencing both IEC60086-2 and American standards (ANSI-7003ZD battery \#675, ANSI7000ZD battery \#13, ANSI-7002ZD battery \#312, and ANSI-7005ZD battery \#0). The American and European standards are not identical, so there are variations in the presentation of results, making it difficult to compare the performance of American manufacturers with that of European manufacturers. Ideally, the adoption of one pattern should be applied in Brazil. Manufacturers should also provide data sheets in Portuguese, which would lead to a better understanding of the product by the reader. This would also make the reader feel valued as a result of their native language being included in the product information.

The results for the size \#675 batteries can be divided into three distinct groups: a group composed of six brands with similar behavior, an intermediate group consisting of three brands with a slight descent in performance, and a final group of one brand with the best performance. Thus, the worst batteries in terms of performance were ClearCell, ExtraPower, icellTech, Sony, Rayovac and Renata (average of 250 hours), the intermediate group comprised Energizer (264 hours), PowerOne (300 hours), and Panasonic (312 hours), and best performance Duracell ( 372 hours).

Battery performance for size \# 13 batteries can also be divided into three groups: a group composed of four brands with similar performance, a second group comprising also four brands with a slight descent in performance, and a third group containing the top two brands. ClearCell,
ExtraPower, icellTech, and Energizer showed the worst performance (240 hours), followed by Panasonic, Duracell, , PowerOne, and Rayovac (264, 276, 276, and 276 hours, respectively), with Renata (300 hours) and Sony (312 hours) showing the best performance.

The results for batteries of size \#312 can be divided into four groups: a first group containing the worst performers, a second group with two brands whose results were slightly higher in relation to the previous group, a third group consisting of five brands with similar results, and a fourth consisting of one brand . Energizer (156 hours) and ExtraPower (168 hours) make up the first group, ClearCell (180 hours) and PowerOne (192 hours) follow in the second group; icellTech, Renata, Sony, Panasonic, and Roayovac (204 hours) comprise the third group, and Duracell (276 hours) in the fourth group.

Three groups can also be used to categorize the behavior of \#10 batteries. The first group is constituted by the four worst performers, followed by a second group with slight higher performance, and finally, the brands with the best performance. ExtraPower and ClearCell (228 hours), PowerOne and Renata (240 hours) constitutes the first group; the second group consists of Duracell, Sony, icellTech, and Energizer ( 252 hours); Panasonic (264 hours) and Rayovac (276 hours) are the brands in the last group.

Zinc-air batteries are usually referred as mercury free, when, in fact, some have mercury in their constitution. For example, icellTech states that they use less than $25 \mathrm{mg}$ of mercury per battery (icellTech, 2004) while Duracell (2008) reports that their batteries satisfy the limit of 0.1 $\mathrm{mg} / \mathrm{m}^{3}$. Zhang, Bruce, and Zhang (2011) state that despite the benefits of reduced mercury in zinc-air batteries, there are still some disadvantages such as limitation of power (low voltage and current), evaporation of the electrolyte (failure due to the entry of air into the battery), adverse reactions arising from the presence of other gases in the environment (e.g., the entry of carbon dioxide can produce solid carbide), and production of solid elements (difficult and costly to dispose of). These authors suggest that lithium-air technology may replace zinc-air batteries in the near future.

Cochlear implants also require batteries, for two functions: operation of the transmission electronic circuit and voltage as well as operation of the modulated radio frequency signal from the antenna external to the implanted module (Clark, 2008; Sit and Sarpeshkar, 2008; Bhoir and Panse, 2009); this leads to high current consumption (Wilson, 2004; Zeng, Rebscher, and Harrison, 2008). It is therefore recommended to test a larger number of manufacturers and models of batteries within the hearing aid conditions of any specific technical standard. Further 
studies could incorporate testing batteries for cochlear implants. In this case, it would be feasible to perform a financial analysis of zinc-air batteries and rechargeable ones, given that the latter are very expensive compared to the former, but may be used several times.

\section{Rechargeable batteries}

Solar Ear distributes rechargeable batteries for hearing aids in Brazil. They sent us eight batteries in sizes $\# 675$ and \#13 to test, plus two solar chargers (Figure 8). These solar charger hearing aid batteries are not charged directly by solar energy, since solar energy is only used to charge the two \#AA batteries inside the charger; instead, the \#AA batteries function as accumulators of electricity for charging the hearing aid batteries. This process is possible because \#AA batteries have a higher load capacity than hearing aid batteries, allowing a controlled discharge of current from \#AA batteries to hearing aid batteries. This also occurs when there is electricity in the internal \#AA batteries controlled by an electronic circuit located in the charger.

As stated in the solar charger user's manual (in English, without references) it is necessary to charge the internal batteries before charging hearing aid batteries. According to this manual, the charging process can be performed in two ways: solar charging (by leaving the charger exposed to sunlight or artificial light) or through an external battery charger. We decided to remove the \#AA batteries from the solar charger and left it for six hours to charge via an external charger (Duracell, CEF14N model not supplied), as shown in Figure 9. We did this because if the batteries were recharged by the \#AA solar charger, this would require 20 hours of exposure to the sun or a light source. Additionally, our laboratory does not have a window that receives direct sunlight, rainfall may have disrupted charging, or the solar charger may even have fallen and been damaged if it was not positioned in a safe place. In urban locations, it is more practical to utilize the convenience of residential electricity, a USB connector (universal serial bus: standard connection to a computer and its peripherals that can rely on a DC power supply), or even power from a car than actual solar energy. This is a result of the difficulty in obtaining direct sunlight for the solar charger, caused by buildings that obscure the availability of natural light in the environment, not to mention loading restrictions on cloudy or rainy days. Therefore, removal of the \#AA batteries and external charging was the best option.

Thus, the \#AA batteries were charged and put back in the solar charger. Then the process of charging the $\# 675$ and \#13 batteries was started, by inserting them into the connectors on the solar charger and waiting until the green LED solar charger light went out. The charging time lasted

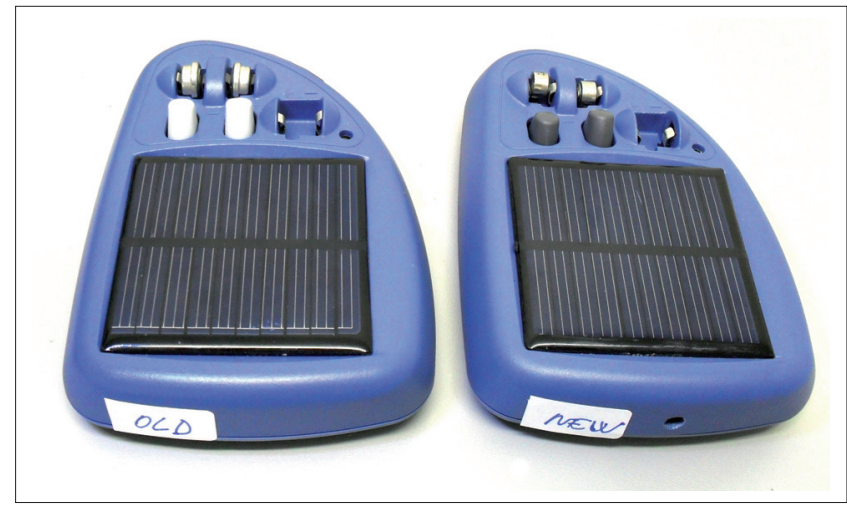

Figure 8. Solar chargers.

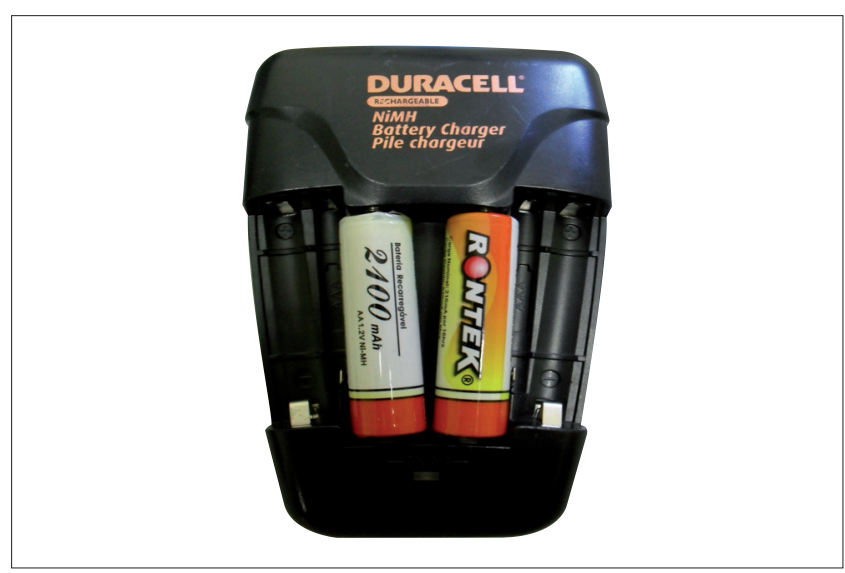

Figure 9. Rechargeable \#AA batteries.

8 hours for $\# 675$ batteries and six hours for $\# 13$ batteries, as stated in the user's manual. During the tests, Solar Ear provided us with a new version of the solar charger which had an input for an external power supply (Figure 8, right), but we preferred to continue to use the first solar charger supplied (Figure 8, left).

According to IEC60086, zinc-air batteries cannot be compared directly with rechargeable batteries, because the former are said to be primary cells while the later are said to secondary batteries. However, such comparison is inevitable in terms of the average service given, which is one of the parameters considered when making the decision regarding use of one battery or the other. Thus, the rechargeable batteries were tested with the same procedures described for zinc-air batteries. In total, eight batteries of both sizes were subjected to tests, the results of which are represented in two formats: as absolute values (Table 3) and as a graphic version (Graphic 5). Solar Ear batteries have proper identification on the anode ( $\mathrm{Ni}-\mathrm{MH}$ cell HL $40 \mathrm{H}$ and $\mathrm{Ni}-\mathrm{MH}$ for $\# 675$ and $\# 13$, respectively), so there was no need for battery identification. 


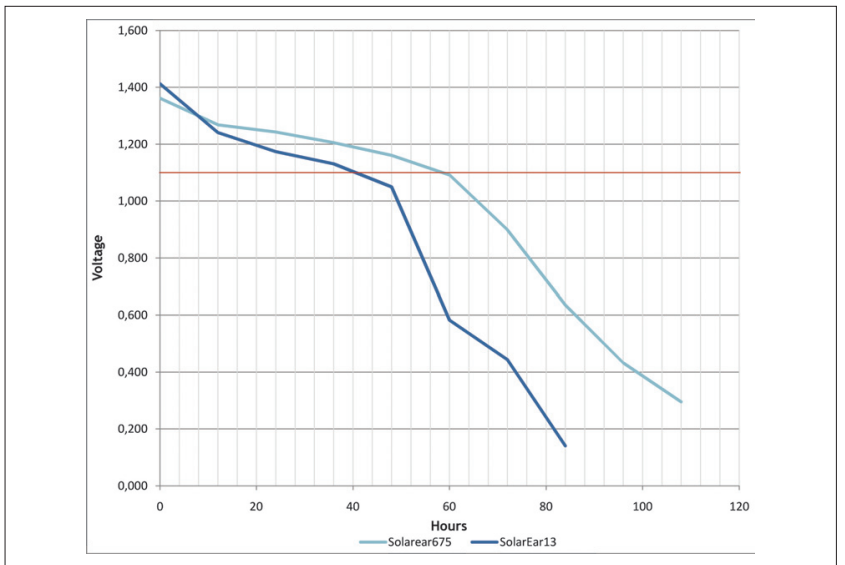

Graphic 5. Discharge curves of Solar Ear rechargeable batteries in sizes \#675 and \#13

Table 3. Rechargeable battery values (average and standard deviation).

\begin{tabular}{lcc}
\hline Size & Average service(hours) & Nominalvoltage(volts) \\
\hline$\# 675$ & $(58 \pm 5)$ & $(1.229 \pm 0.133)$ \\
$\# 13$ & $(36 \pm 10)$ & $(1.240 \pm 0.115)$ \\
\hline
\end{tabular}

Since the data sheets of the rechargeable batteries did not mention test conditions or related regulations, we cannot comment with regards to agreement or disagreement with their respective standards. However, judging by their capacity ( $50 \mathrm{mAh}$ and $18 \mathrm{mAh}$ for \#675 and $\# 13$ batteries, respectively), a higher average service was noted for zinc-air batteries than for rechargeable batteries. This observation is reaffirmed when the results of Tables 1 and 3 are compared. From these tables, it can be seen that $\# 675$ zinc-air batteries had an average service greater than five times that of the same size rechargeable batteries. A similar result was found for \#13 zinc-air and rechargeable batteries (average service seven times greater). The average values of all voltage measurements of zinc-air batteries were superior to those of the rechargeable batteries due to the higher load capacity of zinc-air batteries.

The Solar Ear battery data sheet ( $\mathrm{Ni}-\mathrm{MH}$ cell button technical data) recommends that the cutoff of its products is $1.0 \mathrm{~V}$, which results in a small variation (17\%) of tension relative to their nominal voltage $(1.2 \mathrm{~V})$ as compared with the same parameter of zinc-air batteries for the same value of shear stress (29\%). The same Solar Ear battery data sheet emphasizes that the cutoff for hearing aids is above $1.1 \mathrm{~V}$ as "the battery may be underutilized resulting in insufficient use of the available capacity."

The charge capacity of the rechargeable batteries was 50 and $18 \mathrm{mAh}$ for the $\# 13$ and $\# 675$ sizes, respectively. By way of comparison, the \#675 Duracell battery had a load capacity of $600 \mathrm{mAh}$, which is 12 times that of the same size Solar Ear battery, whereas the \#13 Duracell battery had a load capacity of $290 \mathrm{mAh}$, which is 16 times the capacity of the same size Solar Ear battery.

Varta (Varta Microbattery GmbH, Ellwangen, Germany) produces zinc-air batteries under the brand PowerOne (tested in the present study) as well as the rechargeable ACCU plus series in sizes $\# 675$, \#13, \#312, and \#10 (Varta Material Safety Data Sheet MSDS 2,001,002, $9 / 28 / 2009$ Edition). These have a charger in the format of a pen (pencharger) that works similarly to the Solar Ear model, i.e., it has two \#AAA batteries inside that carry load to hearing aid batteries housed in the charger. Varta also produces a pocket charger (pocketcharger) for $\# 13$, $\# 312$, and \#10 batteries, the energy of which is stored in a rechargeable internal lithium charger. Exclusively for \#675 batteries, Varta has a unique charger model (PowerOne 675 charger). All rechargeable batteries from Varta have a nominal voltage of $1.2 \mathrm{~V}$ that, according to IEC61951-2, provides the following average service values: $74,23,31$, and $12 \mathrm{mAh}$ for $\# 675$, \#13, \#312, and $\# 10$ batteries, respectively. We could not find a distributor of Varta rechargeable batteries in Brazil, so these batteries were not tested in the present study.

In total, 180 zinc-air batteries were acquired (Chart 1) and 96 were tested according to the methodology described. In addition, 16 rechargeable batteries were tested. All the batteries were segregated and will be returned to the manufacturers for disposal.

\section{Leakage}

Energizer (2011) states that zinc-air batteries should neither be recharged or wired in an inverted way nor placed in a short circuit because such events can cause leakage or explosion, and in extreme cases there may be injury to the operator. To prevent leakage, Panasonic (2010) stresses that their zinc-air batteries should not be deformed or mixed or soldered with other batteries. icellTech (2004) adds that its zinc-air batteries cannot be dismantled or placed in a fire as there is a risk of leakage or even explosion. The latter manufacturer stresses that the content of zinc-air batteries can cause irritation or burns to the skin; if this occurs, contamination must be removed with a cloth moistened with soap and water. In the case of contamination of the eyes, they must be 
washed with water for a minimum of 10 minutes and then specialist help should be sought immediately. Duracell (2008) states that in the event of leakage, their zinc-air batteries would release caustic potassium hydroxide, reaching a total volume of $2.5 \mathrm{~mL}$. If there is leakage of the hearing aid battery, the patient should seek assistance directly from the manufacturer of the device, as the use of cleaner can cause stains or irreversible damage to hearing aids. Leaks inside hearing aids invariably and permanently damage electronic components (digital signal processor, microphone, and receiver) and electrics (battery contacts, switches, and wiring). This can be avoided if only batteries from a good supplier within their validity are used and preventive maintenance of hearing aids is performed within the time recommended by the manufacturer.

\section{Accidental intake}

icellTech (2004) explains that continuous exposure to its zinc-air batteries does not cause any harmful effects on health, but in case of ingestion, the advice of a doctor should be sought immediately. However, Duracell (2008) warns that if accidental intake occurs, batteries must be recovered immediately as they can cause burning or perforation of the esophagus; it is not recommended to induce vomiting.

Litovitz et al. (2010) describe a longitudinal study of 8,648 cases of battery ingestion. When lodged in the esophagus, it was possible for batteries to cause severe damage simply within two hours of ingestion. Damage could progress to esophageal perforation, tracheoesophageal fistula appearance, vocal cord paralysis, and even death ( 13 deaths were recorded). Of all the cases of ingestion, $36 \%$ were reported to involve hearing aid batteries. In a previous study with 2,382 cases, Litovitz and Schmitz (1992) reported 952 cases (32\%) of the accidental intake of hearing aid batteries.

\section{Proper disposal}

Brazilian law covers some aspects of battery disposal. From an institutional perspective, the Brazilian Association of the Electrical and Electronics Industry (Associação Brasileira da Indústria Eletro e Eletrônica - ABINEE) maintains a policy of disposal of solid waste based on the National Environmental Council (Conselho Nacional do Meio Ambiente - CONAMA) Resolution 401/2008 called the Reverse Logistics Program for Household Batteries, which has deployed systems and logistics for disposal after the end of life for ordinary batteries, zinc-manganese alkaline batteries, rechargeable batteries, and portable batteries. Zinc-air batteries are a subclass of zinc-manganese batteries. This policy also states the ABINEE goal in Resolution 257/99 of CONAMA, which reads:

"Article $1^{\circ}$ : Batteries in their compositions containing lead, cadmium, and mercury and its compounds, necessary for the operation of any type of equipment, vehicles, or systems, mobile or fixed, as well as electric and electronic products that contain batteries integrated into their structure so that they are not replaceable after energy depletion, will be delivered to users by establishments that sell or network authorized services by the respective industries, to be transferred to manufacturers or importers, so that they adopt, directly or through third parties, the procedures for environmentally sound reuse, recycling, treatment, or disposal."

From the state perspective, the Department of the Environment of São Paulo defined SMA Resolution 38/ 2011, among other guiding "principles of vision and systemic post-consumer responsibility," which implies the direct responsibility of manufacturers, importers, and distributors for their waste, even after the consumption of products, without defining the processes for allocation. A previous law (Law No. 12.300/2006 State, Article 53) has already highlighted the fact that:

"Manufacturers, importers, or distributors of products require or may require special systems for packaging, storage, collection, transportation, treatment, or disposal, in order to avoid damage to the environment and public health, even after consuming their waste from these items, and are responsible for servicing requirements set by the environmental agency."

From the federal perspective, the CONAMA has a National Policy on Solid Waste instituted by Law No. $12.305 / 10$, which provides for the creation of systems of reverse logistics for collection and disposal of electronic products, lubricating oils, fluorescent lamps, packaging in general, and drugs. However, the Ministry itself (Brazil, 2013) warns that "other products, however, as there are already regulations in place in this regard, such as those relating to pesticides and batteries, and tires and oil, working groups were not created to discuss reverse logistics in these chains." However, this legislation appears to lack a comprehensive system that can handle marketing, disposal, collection, allocation, monitoring, evaluation, and feedback.

Within this setting, Panasonic (2010) states that if its zinc-air batteries are thrown to the ground, they will leak electrolyte; they have not, however, assessed the possible resulting environmental damage. Energizer (2011) merely report that "disposal must comply with federal, state, or 
local law" and "technologies such as incineration or landfill should be considered."

\section{CONCLUSION}

It was possible to investigate the performance of ten brands of hearing aid batteries, in addition to describing the procedures recommended for leakage, accidental intake, and disposal.

\section{REFERENCES}

1. Bloom S. Today's hearing aid batteries pack more power into tinier packages. Hearing J. 2003;56(7):17-24.

2. Bocchi N, Ferracin LC, Biaggio SR. Pilhas e baterias: funcionamento e impacto ambiental. Química Nova na Escola. 2000;11:3-9.

3. Brasil. 2013. [cited 2013 Feb 13]. Available from: http:/ /www.mma.gov.br.

4. Cudahy E, Levitt H. Digital hearing aids: a historical perspective. In: Sandlin, RE. Understanding digitally programmable hearing aids. San Diego: Allyn and Bacon; 1994.

5. Duracell. Material Safety data Sheet. Bethel (US): Duracell; 20085 p. Report No.: GMEL\#2019-5.

6. Energizer. Application Manual Zinc-Air (Zn/O2). 4 p. Detroit (US): Energizer; 2004.

7. Energizer. Product Safety Datasheet. Detroit (US): Energizer; 20114 p.

8. Halliday D, Resnick R. Física básica Rio de Janeiro. Livros Técnicos e Científicos; 1988. p. 95-125.

9. Harvey D. Hearing aids. 1st ed. Sydney (Australia): Boomerang Press; 2000.

10. icellTech. Material Safety Data Sheet. Seoul (Korea): icellTech; 2004 3p. Report No.: QP0502-4.

11. Kates JM. Digital hearing aids. Plural Publishing: San Diego; 2008.
12. Knutsen JE. Power Supplies for Hearing Aids. Br J Audiol. 1982;16(3):189-91.

13. Litovitz T, Schmitz BF. Ingestion of Cylindrical and Button Batteries: An Analysis of 2382 Cases. Pediatrics. 1992;89(4):747-57.

14. Litovitz T, Whitaker N, Clark L. Preventing Battery Ingestions: An Analysis of 8648 Cases. Pediatrics. 2011;125(6):1178-83.

15. Lybarger SF. A historical overview. In: Sandlin RE, editor. Handbook of hearing amplification. San Diego: Singular Publishing Group; 1988. p. 01-29.

16. Microbattery. 2013. [cited 2013 Jan 22]. Available from: http://www.microbattery.com.

17. Panasonic. Product Safety Datasheet. Osaka (Japan): Panasonic; 2010 5p.

18. Pinkwart K, TuebkeJ. Thermodynamics and mechanistics. In: Daniel C, Besenhard JO, editors. Handbook of battery materials. Weinhiem (Germany): Wiley-VCH Verlag \& Co. KGaA; 2011. p. 03-26.

19. SDT - Sound Design Technologies. Using DSP hybrids in high power applications. Burlington (Canada); 200712 p. Report No 24561-2.

20. Sparkes C, Lacey NK. A study of mercuric oxide and zinc-air battery life in hearing aids. J Laryngol Otolol. 1987;111(9):814-9.

21. Valente M, Cadieux JH, Flowers L, NewmanJG, Scherer J, Gephart G. Differences in Rust in Hearing Aid Batteries across Four Manufacturers, Four Battery Sizes, and Five Durations of Exposure. J Am Acad Audiolol. 2007; 18(10)846-62.

22. Wei Z, Huang W, Zhang S, Tan J. Carbon-based air electrodes carrying $\mathrm{MnO} 2$ in zinc-air batteries. Journal of Power Sources. 2000;91(2):83-5.

23. ZhangJG, Bruce PG, Zhang XG. Metal-air batteries. In: 24. Daniel C, Besenhard JO, editors. Handbook of battery materials. Weinhiem (Germany): Wiley-VCH Verlag \& Co. KGaA; 2011. p. 759-68. 